\title{
GMR
}

\section{Growth hormone polymorphisms and growth traits in Chinese Tibetan sheep Ovis aries}

\author{
Y.C. Han, Y.G. Sun and Q. Li \\ The Animal Genetics and Breeding Laboratory, \\ Qinghai Academy of Animal Science and Veterinary Medicine, \\ Qinghai University, Xining, China \\ Corresponding author: Y.C. Han \\ E-mail: qhhanyincang@126.com
}

Genet. Mol. Res. 15 (3): gmr.15038397

Received January 7, 2016

Accepted March 18, 2016

Published August 26, 2016

DOI http://dx.doi.org/10.4238/gmr.15038397

Copyright (C) 2016 The Authors. This is an open-access article distributed under the terms of the Creative Commons Attribution ShareAlike (CC BY-SA) 4.0 License.

\begin{abstract}
Growth hormone $(\mathrm{GH})$ plays an important role in promoting growth, protein and muscle accretion, and fat catabolism, suggesting that $\mathrm{GH}$ is a potential candidate gene affecting growth traits in vertebrates. In this paper, polymorphisms in GH were investigated in 632 Chinese Tibetan sheep, by using DNA sequencing. Three single nucleotide polymorphisms were identified, including two mutations (g.616G $>$ A and g.624G $>$ A) in intron 2 and one synonymous mutation $(\mathrm{g} .498 \mathrm{G}>\mathrm{C})$ in exon 2. Association analyses showed that both g.498G $>$ C and g.616G $>$ A were significantly associated with several growth traits (at $\mathrm{P}<0.01$ or $\mathrm{P}<0.05$ ) in three investigated breeds. Our results demonstrate that $\mathrm{GH}$ variation may be used as a molecular marker for growth traits in Chinese Tibetan sheep.
\end{abstract}

Key words: Chinese Tibetan sheep; Growth hormone; Growth traits; SNP 


\section{INTRODUCTION}

The Qinghai-Tibetan plateau is the highest and largest plateau in the world, known for its extremely harsh environment, including high altitude, severe cold, strong UV radiation, and short-growing season (Wiener et al., 2003). Tibetan sheep were the first artificially bred sheep in the natural ecosystem of the Qinghai-Tibetan plateau to adapt well to these conditions (Xin et al., 2011). Undoubtedly, they are an important species of grazing livestock with great economic value and high tolerance to the extreme environments, such as extreme cold, low oxygen concentrations, and low air pressure (Zhou et al., 2015).

Growth hormone $(\mathrm{GH})$, a polypeptide hormone, is synthesized and secreted by the anterior pituitary eosinophil cells in mammals (Nørrelund et al., 2003). Together with other hormones of the somatotropic axis, GH can accelerate metabolism and promote the growth of many organs and tissues (Butler and Le Roith, 2001) that are directly involved in promoting growth, protein and muscle accretion, and fat catabolism (Chen et al., 2015). Zhang et al. (2007) identified two mutations in the third intron of the GH that were associated with abdominal fat in chickens. Jia et al. (2014) identified three novel SNPs in the ovine GH, which can affect growth traits (body weight, body length, body height, and heart girth) in sheep. Two SNPs (C253T and C303T) were identified in the GH promoter region that could affect carcass traits in Japanese Black cattle (Sugita et al., 2014). Similarly, SNPs in bovine GH (bGH), at bGH codons 127 and 172, were shown to affect carcass traits and fatty acid composition in Japanese Black cattle (Ardiyanti et al., 2009). Additionally, in goat, two active SNPs (A781G and $\mathrm{A} 1575 \mathrm{G}$ ) were associated with litter size and superovulation response (Zhang et al., 2011). Taken together, these findings lend credence to the hypothesis that GH is an excellent candidate gene for growth-related traits in livestock.

Thus far, no study has examined the association between SNPs and growth traits in general. Therefore, the present study was performed to identify SNPs in GH of Chinese Tibetan sheep and to evaluate the association of these polymorphisms with growth traits.

\section{MATERIAL AND METHODS}

This study was approved by the Ethics Committee of the Qinghai University (Qinghai, China), and all efforts were made to minimize suffering.

\section{Animal and genomic DNA isolation}

Blood samples were collected from 632 Chinese Tibetan sheep representing three breeds: Black Tibetan sheep (BT, N = 226), Gaoyuan Tibetan sheep (GT, N = 191), and Oula Tibetan sheep (OT, $N=215$ ). These three groups represent the main Chinese breeds that are reared in the Provinces of Qinghai, Gansu, and Henan, respectively. Their growth traits (body weight, body height, body length, and chest circumference) were recorded at 3 years of age.

Genomic DNA was extracted from sheep blood (jugular vein samples) by the standard phenol-chloroform extraction procedure (He et al., 2012). DNA quantity and purity $\left(\mathrm{A}_{260} /\right.$ $\mathrm{A}_{280}$ ratio) for each sample was assessed using a Nano-Drop ${ }^{\mathrm{TM}} 1000$ Spectrometer (Thermo Scientific, Waltam, MA, USA).

Genetics and Molecular Research 15 (3): gmr.15038397 


\section{Primer design and polymerase chain reaction (PCR) conditions}

Primers to amplify the ovine GH gene were designed based on NCBI database sequences (GenBank accession No. NC_019468.1) using the Primer v. 5.0 software (PREMIER Biosoft, Palo Alto, CA, USA). Forward primer 3'-Region-F (5'-CTCCTGGTCTCTCCCTAG-3') and reverse primer $3^{\prime}$-Region-R (5'-GCCACTCACTGATTTCTG-3') were used to amplify a fragment of $532 \mathrm{bp}$ in exons 2 and 3 of the GH gene. A PCR was conducted in $20-\mu \mathrm{L}$ reactions containing $50 \mathrm{ng}$ DNA, $10 \mathrm{pM}$ each primer, $0.20 \mathrm{mM}$ dNTPs, $2.5 \mathrm{mM} \mathrm{MgCl}_{2}$, and $0.5 \mathrm{U}$ Taq DNA polymerase (TaKaRa, Shiga, Japan). The following PCR conditions were used: $5 \mathrm{~min}$ at $95^{\circ} \mathrm{C} ; 35$ cycles of $30 \mathrm{~s}$ at $94^{\circ} \mathrm{C}, 35 \mathrm{~s}$ at $62.8^{\circ} \mathrm{C}, 40 \mathrm{~s}$ at $72^{\circ} \mathrm{C}$; and a final extension at $72^{\circ} \mathrm{C}$ for 10 min. Digested products were detected by electrophoresis on $1.5 \%$ agarose gels.

\section{SNP discovery and genotyping}

Using single-strand conformation polymorphism to detect the three mutations would be time-consuming as well as complicated. Additionally, there are no suitable restriction endonucleases for restriction fragment length polymorphism, which is commonly used to detect mutation genotypes. Thus, the DNA from the 632 Chinese Tibetan sheep was sequenced to distinguish the genotypes of the three mutations in $\mathrm{GH}$.

\section{Statistical analysis}

Genotype and allele frequencies, gene heterozygosity $\left(H_{\mathrm{E}}\right)$, effective allele numbers $\left(N_{\mathrm{E}}\right)$, polymorphism information content (PIC), and tests for deviation from Hardy-Weinberg equilibrium (HWE) were calculated by POPGENE v. 1.32 (Yeh et al., 1997).

The effects of genotype on Chinese Tibetan sheep growth traits were analyzed by the least-square method as applied in the general linear model procedure in SPSS 21 (IBM, Armonk, NY, USA). The following statistical linear model was used: $Y_{i j}=u+G_{i}+S_{i}+E_{i j}$, where $Y_{i j}$ is the trait measured on each of the individual cattle, $u$ is the overall population mean for the trait, $G_{i}$ is the fixed effect associated with the genotype, $S_{i}$ is the fixed effect due to sex, and $E_{i j}$ is the standard error.

\section{RESULTS}

\section{Polymorphisms and genetic diversity}

Sequence analysis of the GH gene revealed three mutations: $\mathrm{G}>\mathrm{C}$ mutation at 498 bp, G>A mutation at $616 \mathrm{bp}$, and $\mathrm{G}>\mathrm{A}$ mutation at $624 \mathrm{bp}$, named g.498G $>\mathrm{C}, \mathrm{g} .616 \mathrm{G}>\mathrm{A}$, and g.624G $>$ A, respectively (Figure 1). The g.616G $>$ A and g.624G $>$ A mutations were located in intron 2, whereas the g.498G $>$ C mutation was located in exon 2 and was a synonymous mutation (Pro87Pro) resulting in no change in the structure of the encoded protein.

The allelic and genotypic frequencies, and the genetic diversity parameters $\left(H_{\mathrm{E}}, N_{\mathrm{E}}\right.$, and PIC) for the SNPs are summarized in Table 1. In three breeds, GG (g.498G $>$ C), GG (g.616G $>$ A), and AA (g.624G $>$ A) were the most prevalent genotypes. A chi-square test showed that g.616G $>$ A and g.624G $>$ A were in HWE $\left(\chi^{2}<\chi_{0.05}{ }^{2}\right)$ in OT sheep, whereas individual genotypic frequencies were severely out of HWE for other SNPs $\left(\chi^{2}>\chi_{0.05}{ }^{2}\right)$. According to the 
conventions for PIC classification (PIC $<0.25$ is considered low, $0.25-0.50$ is intermediate, and $>0.50$ is high polymorphism), our data showed that all SNPs fell in the intermediate polymorphism level.

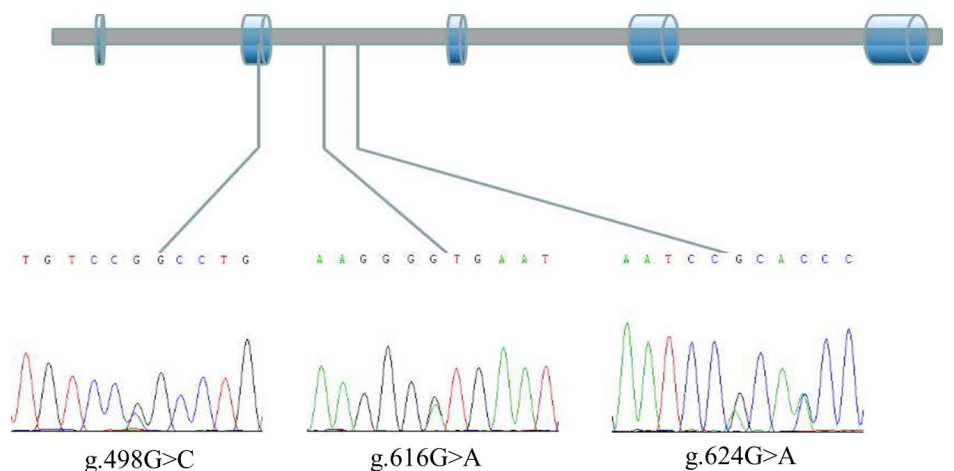

Figure 1. Schematic representation of the GH gene with the localization of the three identified SNPs.

Table 1. Genotype frequencies (\%) of the GH for the SNPs in Chinese Tibetan sheep.

\begin{tabular}{|c|c|c|c|c|c|c|c|c|c|c|}
\hline \multirow{2}{*}{$\begin{array}{l}\text { Site } \\
\text { g.498G }>C\end{array}$} & \multirow{2}{*}{$\begin{array}{c}\text { Breed } \\
\mathrm{e}\end{array}$} & \multicolumn{3}{|c|}{ Genotypic frequency } & \multicolumn{2}{|c|}{ Allele frequency } & \multirow[t]{2}{*}{$H_{\mathrm{E}}$} & \multirow[t]{2}{*}{$N_{\mathrm{E}}$} & \multirow[t]{2}{*}{ PIC } & \multirow[t]{2}{*}{$\chi^{2}$ (HWE*) } \\
\hline & & GG & $\mathrm{GC}$ & $\mathrm{CC}$ & G & $\mathrm{C}$ & & & & \\
\hline & BT & 0.5885 & 0.2566 & 0.1549 & 0.7168 & 0.2832 & 0.4060 & 1.6835 & 0.3236 & 30.5830 \\
\hline & GT & 0.4869 & 0.3141 & 0.1990 & 0.6440 & 0.3560 & 0.4585 & 1.8469 & 0.3534 & 18.9425 \\
\hline & OT & 0.4744 & 0.3628 & 0.1628 & 0.6558 & 0.3442 & 0.4514 & 1.8230 & 0.3495 & 8.2913 \\
\hline \multirow[t]{4}{*}{ g. $616 \mathrm{G}>\mathrm{A}$} & & GG & GA & AA & G & A & & & & \\
\hline & BT & 0.5664 & 0.2965 & 0.1372 & 0.7146 & 0.2854 & 0.4079 & 1.6889 & 0.3247 & 16.8670 \\
\hline & GT & 0.5759 & 0.3089 & 0.1152 & 0.7304 & 0.2696 & 0.3939 & 1.6498 & 0.3163 & 8.8878 \\
\hline & OT & 0.5163 & 0.4047 & 0.0791 & 0.7186 & 0.2814 & 0.4044 & 1.6790 & 0.3226 & 0.0001 \\
\hline \multirow[t]{4}{*}{ g. $624 \mathrm{G}>\mathrm{A}$} & & GG & GA & AA & G & A & & & & \\
\hline & BT & 0.4867 & 0.2965 & 0.2168 & 0.6350 & 0.3650 & 0.4636 & 1.8642 & 0.3561 & 29.3694 \\
\hline & GT & 0.4712 & 0.3194 & 0.2094 & 0.6309 & 0.3691 & 0.3573 & 0.4657 & 0.3573 & 18.8635 \\
\hline & OT & 0.4698 & 0.3814 & 0.1488 & 0.6605 & 0.3395 & 0.4485 & 1.8132 & 0.3479 & 4.8133 \\
\hline
\end{tabular}

HWE, Hardy-Weinberg equilibrium; $\chi_{0.05}^{2}=5.991, \chi_{0.01}^{2}=9.210$.

\section{Effect of the polymorphism locus on growth traits in BT sheep}

The association analysis between each marker and the growth traits in BT sheep is shown in Table 2. For g.498G $>$ C, individuals with genotype GG had increased body weight and body length compared to the $\mathrm{CC}$ genotype $(\mathrm{P}<0.05)$. For g.616G $>\mathrm{A}$, individuals with genotype AA had higher values than those with $\mathrm{GG}$ and $\mathrm{GA}$ on body weight $(\mathrm{P}<0.05)$. Unlike the other mutations, g. $624 \mathrm{G}>\mathrm{A}$ genotypes did not show any significant correlations with any of the measured growth traits $(\mathrm{P}>0.05)$.

\section{Effect of the polymorphism locus on growth traits in GT sheep}

Table 3 shows the effects of the SNPs on growth traits in GT sheep. For g.498G $>$ C, individuals with genotype GG had higher values than those with $\mathrm{CC}$ for body weight, body height, body length, and chest circumference $(\mathrm{P}<0.01)$. Additionally, the body height and body length of individuals with genotype $\mathrm{GC}$ were higher than those with genotype $\mathrm{CC}(\mathrm{P}<$

Genetics and Molecular Research 15 (3): gmr.15038397 
0.05). For g.616G $>A$, individuals with genotype AA had higher values than those with GG on body weight $(\mathrm{P}<0.05)$, while genotype AA had higher mean values for body length than those with genotype GG $(\mathrm{P}<0.01)$. As observed in the BT sheep, there were no significant correlations between g.624G $>\mathrm{A}$ and any of the growth traits.

Table 2. Association of different genotypes of SNPs in GH with growth traits in BT sheep.

\begin{tabular}{l|c|c|c|c|c}
\hline Site & Genotypes & Body weight $(\mathrm{cm})$ & Body height $(\mathrm{cm})$ & Body length $(\mathrm{cm})$ & Chest circumference $(\mathrm{cm})$ \\
\hline \multirow{3}{*}{ g.498G $>$ C } & GG & $43.52 \pm 3.18^{\mathrm{a}}$ & $64.85 \pm 5.29$ & $69.30 \pm 6.12^{\mathrm{a}}$ & $89.09 \pm 8.21$ \\
\cline { 2 - 6 } & GC & $41.33 \pm 3.59$ & $65.41 \pm 5.37$ & $67.24 \pm 6.52$ & $88.92 \pm 8.59$ \\
\cline { 2 - 6 } & CC & $40.75 \pm 4.82^{\mathrm{b}}$ & $64.38 \pm 6.92$ & $66.39 \pm 6.39^{\mathrm{b}}$ & $88.03 \pm 8.22$ \\
\hline \multirow{2}{*}{ g.616G $>$ A } & GG & $41.88 \pm 3.58^{\mathrm{b}}$ & $64.53 \pm 7.25$ & $68.12 \pm 7.69$ & $88.84 \pm 7.60$ \\
\cline { 2 - 6 } & GA & $41.98 \pm 3.27^{\mathrm{b}}$ & $65.22 \pm 6.39$ & $68.16 \pm 7.30$ & $88.83 \pm 7.38$ \\
\hline \multirow{2}{*}{ g.624G $>$ A } & AA & $44.75 \pm 3.97^{\mathrm{a}}$ & $65.38 \pm 6.77$ & $68.99 \pm 6.52$ & $89.03 \pm 8.26$ \\
& GG & $42.04 \pm 3.89$ & $64.41 \pm 5.92$ & $67.92 \pm 5.55$ & $88.52 \pm 7.21$ \\
\cline { 2 - 6 } & GA & $42.29 \pm 4.11$ & $65.37 \pm 5.40$ & $68.33 \pm 5.96$ & $88.97 \pm 7.52$ \\
\cline { 2 - 6 } & AA & $43.96 \pm 4.54$ & $65.44 \pm 6.29$ & $69.20 \pm 6.71$ & $89.57 \pm 7.70$ \\
\hline
\end{tabular}

Means with different superscript lower case letters are significantly different at $\mathrm{P}<0.05$.

Table 3. Association of different genotypes of SNPs in GH with growth traits in GT sheep.

\begin{tabular}{l|c|c|c|c|c}
\hline Site & Genotypes & Body weight $(\mathrm{cm})$ & Body height $(\mathrm{cm})$ & Body length $(\mathrm{cm})$ & Chest circumference $(\mathrm{cm})$ \\
\hline g.498G $>$ C & GG & $46.71 \pm 3.92^{\mathrm{A}}$ & $67.28 \pm 5.62^{\mathrm{A}}$ & $70.34 \pm 6.36^{\mathrm{A}}$ & $93.32 \pm 8.69^{\mathrm{A}}$ \\
\cline { 2 - 6 } & GC & $45.42 \pm 3.59^{\mathrm{A}}$ & $66.67 \pm 5.28^{\mathrm{a}}$ & $69.98 \pm 6.55^{\mathrm{a}}$ & $90.42 \pm 9.11$ \\
\cline { 2 - 6 } & CC & $40.18 \pm 4.29^{\mathrm{B}}$ & $62.50 \pm 6.36^{\mathrm{Bb}}$ & $65.72 \pm 7.21^{\mathrm{Bb}}$ & $88.68 \pm 7.20^{\mathrm{B}}$ \\
\hline \multirow{2}{*}{ g.616G $>\mathrm{A}$} & GG & $44.31 \pm 3.28$ & $65.77 \pm 5.88$ & $68.32 \pm 5.59^{\mathrm{B}}$ & $90.92 \pm 8.52$ \\
\cline { 2 - 6 } & GA & $45.80 \pm 5.44$ & $66.48 \pm 5.30$ & $69.98 \pm 6.21$ & $91.78 \pm 7.22$ \\
\cline { 2 - 6 } & AA & $46.35 \pm 4.26$ & $67.06 \pm 6.88$ & $72.44 \pm 6.67^{\mathrm{A}}$ & $93.48 \pm 7.89$ \\
\hline g.624G $>$ A & GG & $44.22 \pm 3.47$ & $65.32 \pm 6.25$ & $68.68 \pm 5.77$ & $90.85 \pm 7.92$ \\
\cline { 2 - 6 } & GA & $45.62 \pm 3.95$ & $66.86 \pm 6.65$ & $69.36 \pm 5.10$ & $91.63 \pm 7.88$ \\
\cline { 2 - 6 } & AA & $45.83 \pm 4.62$ & $66.88 \pm 6.74$ & $70.64 \pm 6.82$ & $92.67 \pm 9.32$ \\
\hline
\end{tabular}

Means with different superscript lower and upper case letters are significantly different at $\mathrm{P}<0.05$ and $\mathrm{P}<0.01$, respectively.

\section{Effect of the polymorphism locus on growth traits in OT sheep}

The association results of single markers with the four growth traits in OT sheep are shown in Table 4. For g.498G $>$ C, individuals with genotype GG had higher values than those with $\mathrm{CC}$ for body weight and body length $(\mathrm{P}<0.01)$. In addition, the body weights of individuals with genotype GG were higher than those with genotype GC $(\mathrm{P}<0.05)$. For g.616G $>A$, significant differences in body weight were observed between the AA and GG genotypes $(\mathrm{P}<0.05)$. Compared with $\mathrm{GG}$, individuals with the AA genotype showed better performance for body length $(\mathrm{P}<0.01)$. Again, no significant correlations were observed in any of the growth traits for $\mathrm{g} .624 \mathrm{G}>\mathrm{A}$.

Genetics and Molecular Research 15 (3): gmr.15038397 
Table 4. Association of different genotypes of SNPs in GH with growth traits in OT sheep.

\begin{tabular}{l|c|c|c|c|c}
\hline Site & Genotypes & Body weight $(\mathrm{cm})$ & Body height $(\mathrm{cm})$ & Body length $(\mathrm{cm})$ & Chest circumference $(\mathrm{cm})$ \\
\hline \multirow{3}{*}{ g.498G $>$ C } & GG & $61.01 \pm 4.25^{\mathrm{Aa}}$ & $73.32 \pm 5.24$ & $76.44 \pm 6.80^{\mathrm{A}}$ & $93.38 \pm 9.58$ \\
\cline { 2 - 6 } & GC & $56.43 \pm 5.18^{\mathrm{b}}$ & $73.05 \pm 5.85$ & $75.29 \pm 7.64^{\mathrm{A}}$ & $92.37 \pm 9.26$ \\
\cline { 2 - 6 } & CC & $52.71 \pm 5.53^{\mathrm{Bc}}$ & $73.013 \pm 7.43$ & $70.65 \pm 6.57^{\mathrm{B}}$ & $91.13 \pm 7.66$ \\
\hline \multirow{2}{*}{ g.616G>A } & GG & $57.35 \pm 3.56^{\mathrm{b}}$ & $72.32 \pm 6.95^{\mathrm{B}}$ & $74.44 \pm 6.63^{\mathrm{b}}$ & $91.38 \pm 7.26^{\mathrm{B}}$ \\
\cline { 2 - 6 } & GA & $57.79 \pm 5.21^{\mathrm{b}}$ & $73.11 \pm 7.36^{\mathrm{b}}$ & $75.18 \pm 7.19$ & $92.27 \pm 7.57^{\mathrm{B}}$ \\
\cline { 2 - 6 } & AA & $63.29 \pm 5.22^{\mathrm{a}}$ & $79.05 \pm 7.62^{\mathrm{Aa}}$ & $78.76 \pm 7.85^{\mathrm{a}}$ & $102.85 \pm 9.84^{\mathrm{A}}$ \\
\hline g.624G>A & GG & $57.75 \pm 4.89$ & $72.81 \pm 7.51$ & $75.01 \pm 6.62$ & $92.38 \pm 9.25$ \\
\cline { 2 - 6 } & GA & $57.88 \pm 4.28$ & $73.37 \pm 5.83$ & $75.12 \pm 7.36$ & $92.78 \pm 9.81$ \\
\cline { 2 - 6 } & AA & $59.08 \pm 4.15$ & $73.81 \pm 5.26$ & $75.21 \pm 7.59$ & $93.15 \pm 7.50$ \\
\hline
\end{tabular}

Means with different superscript lower and upper case letters are significantly different at $\mathrm{P}<0.05$ and $\mathrm{P}<0.01$, respectively.

\section{DISCUSSION}

In the process of livestock breeding, growth traits are considered to be a crucial tool to assess the economic value of animals. These growth traits are affected by many factors, such as genotype, sex, age, breed, nutritional level, and other environmental factors (Gui et al., 2014). Accumulating evidence suggests that the candidate gene approach is one of many methods suitable for analysis of the association between gene polymorphism and phenotypes, which is a promising strategy for the genetic improvement of economically important quantitative traits (Edmunds et al., 2009; Periasamy et al., 2014). GH is a single-chain polypeptide hormone mainly secreted by somatotropes of the anterior pituitary gland and is an important regulator of somatic growth in almost all vertebrates (Thomas et al., 2007; Rak and Gregoraszczuk, 2008; Delgadin et al., 2015; Odle et al., 2015). Therefore, we hypothesized that GH might be associated with growth traits in Chinese Tibetan sheep.

In the present study, we detected one SNP (g.498G $>$ C) in an exon and another two SNPs (g.616G $>$ A and g.624G $>$ A) mapped to introns, revealing their associations with growth traits in Chinese Tibetan sheep. Except for g.624G $>$ A, both g.498G $>$ C and g.616G $>$ A were found to affect many growth traits. Specifically, at the g.498G $>$ C locus, individuals with genotype GG had significantly greater body weight and body length in all breeds, compared with genotype $\mathrm{CC}$. This suggests that the $\mathrm{G}$ allele might be associated with an increase in body weight and body length. At the g.498G $>$ C locus, individuals with genotype AA had significantly greater body weight in all breeds, compared with genotype GG. Thus, the A allele appeared to be the beneficial genotype for body weight.

We noted that g.498G $>C$ was a synonymous mutation and that g.616G $>$ A was located in the intron region. Neither of the SNPs changed the structure of the encoded proteins, but our results demonstrated that they were still associated with some of the growth traits. There are two main reasons for these results: 1) such associations may be the result of linkage disequilibrium between these SNPs and other genes on the same chromosome that have significant effects on the growth traits studied here (Li et al., 2013). 2) Mutations could also affect both the splice donor site or nearby regions and regulatory motifs (Van Laere et al., 2003; Capon et al., 2004; Nackley et al., 2006; Krawczak et al., 2007). Further verifications are needed for understanding the underlying mechanisms.

Genetics and Molecular Research 15 (3): gmr.15038397 
In summary, genotyping and association analyses performed on the g.498G $>C$ and g.616G $>$ A demonstrated that these SNPs were significantly associated with growth traits. Hence, our findings suggest that GH could be used as a genetic marker for marker assisted selection (MAS) during animal breeding for excellent growth traits. We recommend that further research be performed by including a larger population size before its application in MAS.

\section{Conflicts of interest}

The authors declare no conflict of interest.

\section{ACKNOWLEDGMENTS}

Research supported by the Science and Technology Department Project of Qinghai Province (\#2013-N-517) and the Spark Program of National Science and Technology Ministry (\#2014GA870001).

\section{REFERENCES}

Ardiyanti A, Oki Y, Suda Y, Suzuki K, et al. (2009). Effects of GH gene polymorphism and sex on carcass traits and fatty acid compositions in Japanese Black cattle. Anim. Sci. J. 80: 62-69. http://dx.doi.org/10.1111/j.1740-0929.2008.00594.x

Butler AA and Le Roith D (2001). Control of growth by the somatropic axis: growth hormone and the insulin-like growth factors have related and independent roles. Annu. Rev. Physiol. 63: 141-164. http://dx.doi.org/10.1146/annurev. physiol.63.1.141

Capon F, Allen MH, Ameen M, Burden AD, et al. (2004). A synonymous SNP of the corneodesmosin gene leads to increased mRNA stability and demonstrates association with psoriasis across diverse ethnic groups. Hum. Mol. Genet. 13: 2361-2368. http://dx.doi.org/10.1093/hmg/ddh273

Chen D, Liu J, Chen W, Shi S, et al. (2015). Expression and ontogeny of growth hormone (Gh) in the protogynous hermaphroditic ricefield eel (Monopterus albus). Fish Physiol. Biochem. 41: 1515-1525. http://dx.doi.org/10.1007/ s10695-015-0104-3

Delgadin TH, Pérez Sirkin DI, Di Yorio MP, Arranz SE, et al. (2015). GH, IGF-I and GH receptors mRNA expression in response to growth impairment following a food deprivation period in individually housed cichlid fish Cichlasoma dimerus. Fish Physiol. Biochem. 41: 51-60. http://dx.doi.org/10.1007/s10695-014-0005-x

Edmunds RC, Hillersøy G, Momigliano P and van Herwerden L (2009). Classic approach revitalizes genomics: Complete characterization of a candidate gene for thermal adaptation in two coral reef fishes. Mar. Genomics 2: 215-222. http:// dx.doi.org/10.1016/j.margen.2009.11.001

Gui L, Wang H, Wei S, Zhang Y, et al. (2014). Molecular characterization, expression profiles, and analysis of Qinchuan cattle SIRT1 gene association with meat quality and body measurement traits (Bos taurus). Mol. Biol. Rep. 41: 52375246. http://dx.doi.org/10.1007/s11033-014-3393-1

He R, Chang Z and Fan J (2012). Genomic DNA isolation and optimization for ISSR reaction system of Tussilago farfara L. Chin. Agr. Sci. Bull 28: 236-241.

Jia JL, Zhang LP, Wu JP, Ha ZJ, et al. (2014). Study of the correlation between GH gene polymorphism and growth traits in sheep. Genet. Mol. Res. 13: 7190-7200. http://dx.doi.org/10.4238/2014.September.5.5

Krawczak M, Thomas NS, Hundrieser B, Mort M, et al. (2007). Single base-pair substitutions in exon-intron junctions of human genes: nature, distribution, and consequences for mRNA splicing. Hum. Mutat. 28: 150-158. http://dx.doi. org/10.1002/humu.20400

Li M, Sun X, Hua L, Lai X, et al. (2013). SIRT1 gene polymorphisms are associated with growth traits in Nanyang cattle. Mol. Cell. Probes 27: 215-220. http://dx.doi.org/10.1016/j.mcp.2013.07.002

Nackley AG, Shabalina SA, Tchivileva IE, Satterfield K, et al. (2006). Human catechol-O-methyltransferase haplotypes modulate protein expression by altering mRNA secondary structure. Science 314: 1930-1933. http://dx.doi. org $/ 10.1126 /$ science. 1131262

Nørrelund H, Djurhuus C, Jørgensen JO, Nielsen S, et al. (2003). Effects of GH on urea, glucose and lipid metabolism, and insulin sensitivity during fasting in GH-deficient patients. Am. J. Physiol. Endocrinol. Metab. 285: E737-E743. http://dx.doi.org/10.1152/ajpendo.00092.2003

Genetics and Molecular Research 15 (3): gmr.15038397 
Odle AK, Drew PD and Childs GV (2015). Giant mice reveal new roles for GH in regulating the adipose immune microenvironment. Endocrinology 156: 1613-1615.http://dx.doi.org/10.1210/en.2015-1205

Periasamy K, Pichler R, Poli M, Cristel S, et al. (2014). Candidate gene approach for parasite resistance in sheep-variation in immune pathway genes and association with fecal egg count. PLoS One 9: e88337.http://dx.doi.org/10.1371/ journal.pone. 0088337

Rak A and Gregoraszczuk EŁ (2008). Local feedback loop of ghrelin-GH in the pig ovary: action on estradiol secretion, aromatase activity and cell apoptosis. Growth Horm. IGF Res. 18: 221-227. http://dx.doi.org/10.1016/j. ghir.2007.09.004

Sugita H, Ardiyanti A, Yokota S, Yonekura S, et al. (2014). Effect of single nucleotide polymorphisms in GH gene promoter region on carcass traits and intramuscular fatty acid compositions in Japanese Black cattle. Livest. Sci. 165: 15-21. http://dx.doi.org/10.1016/j.livsci.2014.04.026

Thomas MG, Enns RM, Shirley KL, Garcia MD, et al. (2007). Associations of DNA polymorphisms in growth hormone and its transcriptional regulators with growth and carcass traits in two populations of Brangus bulls. Genet. Mol. Res. 6: $222-237$.

Van Laere AS, Nguyen M, Braunschweig M, Nezer C, et al. (2003). A regulatory mutation in IGF2 causes a major QTL effect on muscle growth in the pig. Nature 425: 832-836. http://dx.doi.org/10.1038/nature02064

Wiener G, Jianlin H and Ruijun L (2003). The yak. 2nd edn. Regional Office for Asia and the Pacific, Food and Agriculture Organization of the United Nations, Bangkok.

Xin GS, Long RJ, Guo XS, Irvine J, et al. (2011). Blood mineral status of grazing Tibetan sheep in Northeast of the Qinghai-Tibetan Plateau. Livest. Sci. 136: 102-107. http://dx.doi.org/10.1016/j.livsci.2010.08.007

Yeh FC, Yang RC, Boyle TBJ, Ye ZH, et al. (1997). POPGENE: The user-friendly shareware for population genetic analysis. Molecular Biology and Biotechnology Centre, University of Alberta, Canada.

Zhang C, Liu Y, Huang K, Zeng W, et al. (2011). The association of two single nucleotide polymorphisms (SNPs) in growth hormone $(\mathrm{GH})$ gene with litter size and superovulation response in goat-breeds. Genet. Mol. Biol. 34: 49-55. http://dx.doi.org/10.1590/S1415-47572010005000110

Zhang XL, Jiang X, Liu YP, Du HR, et al. (2007). Identification of Avai polymorphisms in the third intron of GH gene and their associations with abdominal fat in chickens. Poult. Sci. 86: 1079-1083. http://dx.doi.org/10.1093/ps/86.6.1079

Zhou JW, Mi JD, Titgemeyer EC, Guo XS, et al. (2015). A comparison of nitrogen utilization and urea metabolism between Tibetan and fine-wool sheep. J. Anim. Sci. 93: 3006-3017. http://dx.doi.org/10.2527/jas.2014-8865

Genetics and Molecular Research 15 (3): gmr.15038397 